\title{
Correction to: Characteristics Associated with Pathologic Nodal Burden in Patients Presenting with Clinical Melanoma Nodal Metastasis
}

\author{
Minyoung Kwak, MD', Yun Song, $\mathrm{MD}^{2}$, Phyllis A. Gimotty, $\mathrm{PhD}^{3}$, Norma E. Farrow, $\mathrm{MD}^{4}$, \\ Andrew D. Tieniber, $\mathrm{MD}^{2}$, Jonathan G. Davick, $\mathrm{MD}^{5}$, Gabriella N. Tortorello, $\mathrm{MD}^{2}$, Georgia M. Beasley, $\mathrm{MD}^{4}$, \\ Craig L. Slingluff Jr. , MD ${ }^{1}$, and Giorgos C. Karakousis, $\mathrm{MD}^{2}$ \\ ${ }^{1}$ Department of Surgery, University of Virginia Health System, Charlottesville, VA; ${ }^{2}$ Department of Surgery, Division of \\ Endocrine and Oncologic Surgery, Hospital of the University of Pennsylvania, Perelman School of Medicine, University of \\ Pennsylvania, Philadelphia, PA; ${ }^{3}$ Department of Biostatistics, Epidemiology, and Informatics, University of Pennsylvania, \\ Philadelphia, PA; ${ }^{4}$ Department of Surgery, Duke University School of Medicine, Durham, NC; ${ }^{5}$ Department of Pathology, \\ University of Virginia Health System, Charlottesville, VA
}

CORRECTION TO: ANN SURG ONCOL (2019) 26:3962-3971 HTTPS://DOI.ORG/10.1245/S10434-01907694-0

In the original article, there is an error in the funding information. The correct funding information is as follows:
Partial funding was provided by the National Cancer Institute (Grant Nos. T32-CA009109-41 and T32CA93245-13), by a Farrow Fellowship, and by the Rebecca Clay Harris Memorial Fellowship.

Publisher's Note Springer Nature remains neutral with regard to jurisdictional claims in published maps and institutional affiliations.

The original article can be found online at https://doi.org/10.1245/ s10434-019-07694-0.

(C) Society of Surgical Oncology 2019

Published Online: 31 October 2019

G. C. Karakousis, MD

e-mail: Giorgos.Karakousis@uphs.upenn.edu 